\title{
On the Relationship Between the Signature of Close Electric Field and the Equivalent Corona Current in Lightning Return Stroke Models
}

\author{
Vernon Cooray, Vladimir A. Rakov, Fellow, IEEE, Farhad Rachidi, Senior Member, IEEE, \\ Raul Montaño, Member, IEEE, and Carlo Alberto Nucci, Fellow, IEEE
}

\begin{abstract}
Engineering return stroke models can be categorized either as current generation (traveling current source type) models or current propagation (transmission line type) models. The current generation models are described among other parameters by a corona current distributed along the channel. Recent studies show that there is equivalence between the models of current generation and current propagation types. Due to this equivalence, any engineering return stroke model of current propagation type can be described in terms of an equivalent corona current per unit channel length. The measurements conducted within 10-500 $\mathrm{m}$ from triggered lightning flashes show that the electric field of subsequent return strokes at these distances flattens within $15 \mu$ s or so. In this paper, the constraints imposed by this feature on the temporal and spatial variation of the equivalent corona current are investigated. The results show that in order for the close fields to flatten within $15 \mu$ s or so, the equivalent corona current, should be bipolar and the corona current wave shape at late times should be identical to that of the longitudinal current time derivative. This is in contrast to most of the engineering models of current generation type, in which the corona current is assumed to be unipolar.
\end{abstract}

Index Terms-Equivalent corona current, lightning electric field, return stroke models.

\section{INTRODUCTION}

$\mathbf{M}$ EASUREMENTS conducted in the vicinity of triggered lightning return strokes show that the electric field within about $500 \mathrm{~m}$ of the channel flattens within $15 \mu$ s or so [1], [2]. Several examples of such fields are shown in Fig. 1.

The engineering return stroke models available in the literature can be divided into current generation and current propagation categories or types, which are also referred to as the traveling current source and transmission line type models, respectively. In the current generation models, the lightning channel itself generates the return stroke current as a result of the neutralization of the charge deposited by the leader in the corona sheath. The main input parameter in these models is the corona current per unit length, which represents the current generated

Manuscript received May 3, 2007; revised October 1, 2007. First published August 26, 2008; current version published November 20, 2008.

V. Cooray is with the Division for Electricity and Lightning Research, Ångström Laboratory, Uppsala University, S-75121 Uppsala, Sweden (e-mail: vernon.cooray@ angstrom.uu.se).

V. A. Rakov is with the Department of Electrical and Computer Engineering, University of Florida, Gainesville, FL 32611 USA.

F. Rachidi is with the EMC Group, Swiss Federal Institute of Technology, CH-1015 Lausanne, Switzerland.

R. Montaño is with the High Voltage Valley, SE 77128 Ludvika, Sweden.

C. A. Nucci is with the Department of Electrical Engineering, University of Bologna, 40125 Bologna, Italy.

Digital Object Identifier 10.1109/TEMC.2008.926918
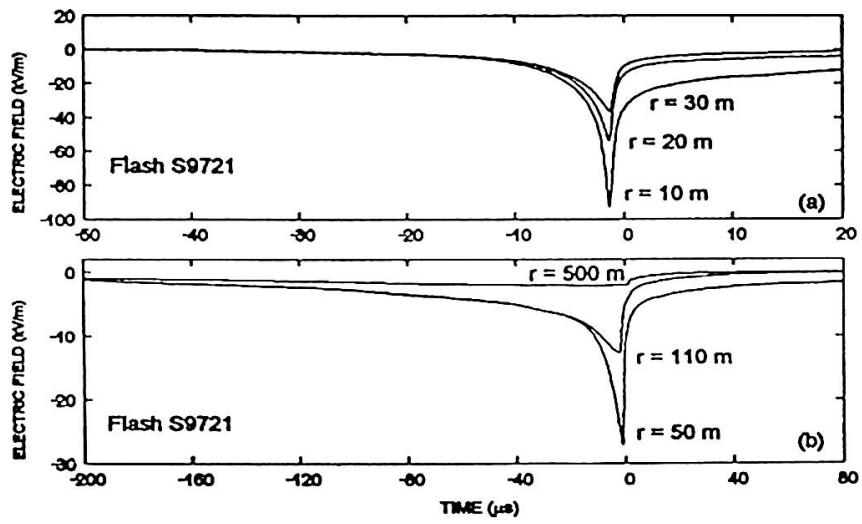

Fig. 1. Typical examples of electric fields measured within $500 \mathrm{~m}$ of the triggered lightning return stroke. Note that the return stroke field starts at $t=0$. The field before this time is due to the dart leader [1]

by a given channel element. In the current propagation models, the return stroke channel acts as a wave guiding structure along which the current injected at the strike point propagates toward the cloud. Recently, Cooray [3] and Maslowski and Rakov [23] showed that there is an equivalency between these two descriptions and that the current propagation models, for example transmission line (TL) [4], modified transmission line exponential (MTLE) [5], and modified transmission line linear (MTLL) [6], can also be represented as current generation models with an equivalent corona current. ${ }^{1}$ Based on this equivalency, for any engineering return stroke model available in the literature, one can define an equivalent corona current. The equivalent corona current of any return stroke model is given by [3]

$$
I_{c}(z, t)=-\frac{\partial I(z, t)}{\partial z}+\frac{1}{c} \frac{\partial I(z, t)}{\partial t}
$$

where $I_{c}(z, t)$ is the corona current per unit length at height $z$, $I(z, t)$ is the longitudinal return stroke current at the same height, as prescribed by the adopted return stroke model, and $c$ is the speed of light in free space. The purpose of this paper is to derive the constraints on the corona current imposed by the experimental observations described earlier. Although the approach described is applicable to any return stroke model available in the literature, the emphasis will be on current propagation models for which Cooray [3] predicted that the equivalent corona current should be bipolar.

\footnotetext{
${ }^{1}$ Rachidi and Nucci [7] had previously shown this equivalency for the MTLE model.
} 


\section{Constraints On The CORONA CuRREnT}

Let us assume that the lightning channel is straight and vertical. The longitudinal current at a given point along the channel at time $t$ is $I(z, t)$. Assume for the moment that the return stroke speed is constant. Given this information, the equivalent corona current can be extracted from (1). The time derivative of the electric field at a point located at distance $D$ from the base of the channel is given by [3] and [8]

$$
\begin{aligned}
\frac{d E_{z}(t, D)}{d t}= & \frac{1}{2 \pi \varepsilon_{o}} \int_{o}^{H} \frac{\sin \theta}{R^{2}} \frac{d Q_{1}(z, t-R / c)}{d t} d z \\
& +\frac{1}{2 \pi \varepsilon_{o}} \int_{o}^{H} \frac{\sin \theta(1-\sin \theta)}{R^{2}} \frac{\partial Q_{2}(z, t-R / c)}{\partial t} d z \\
& +\frac{1}{2 \pi \varepsilon_{o}} \int_{o}^{H} \frac{\left(1-3 \sin ^{2} \theta\right)}{c R^{2}} \frac{\partial I(z, t-R / c)}{\partial t} d z \\
& +\frac{1}{2 \pi \varepsilon_{o}} \int_{o}^{H} \frac{\cos ^{2} \theta}{c^{2} R} \frac{\partial^{2} I(z, t-R / c)}{\partial t^{2}} d z
\end{aligned}
$$

with

$$
Q_{1}(z, t-R / c)=\int_{z / v}^{t-R / c} I_{c}(z, t-R / c) d t
$$

and

$$
Q_{2}(z, t-R / c)=-\frac{I(z, t-R / c)}{c}
$$

where $I_{c}(z, t)$ is the corona current per unit length at height $z, \sin \theta=z / R, R=\sqrt{z^{2}+D^{2}}, H$ is the height of the return stroke channel that contributes to the electric field at time $t$, $Q_{1}(t, z)$ is the total positive charge per unit length deposited on the channel element at height $z$ by the corona current and $Q_{2}(t, z)$ represents the instantaneous charge (negative) flowing across that channel element at that time. The first two components in (2) represent the time derivative of the static field, the third and the fourth terms represent the time derivatives of the induction and radiation terms, respectively. No direct measurements of the current at different heights along the lightning channel are available in the literature and are unlikely to be available in the near future. Thus, indirect methods have to be utilized in constructing engineering models to specify how the lightning current varies as the return stroke propagates upward. It appears that the best means available for this purpose today is the temporal and spatial variation of the optical radiation generated by lightning return strokes. Indeed, the experimental data obtained for electrical discharges having current amplitudes similar to those of lightning [9] and for triggered lightning [18], show that the initial part of the optical radiation generated by a discharge channel element in air is qualitatively similar to that of the current waveform flowing through it. The best data set available today on the spatial and temporal variation of the optical radiation signal generated by the lightning channel is due to Jordan et al. [10], [19]. This shows that the initial peak amplitude of the optical radiation decreases with height while its rise time increases with height. Another interesting observation pertinent to this data set is that, after the initial peak, the tail of the optical pulse does not vary significantly with height, at least over the first few hundred meters. It is not unreasonable to assume that the return stroke current also behaves in this manner. If this is the case for the return stroke current, for times longer than about $t_{o}$ (a value to be specified later), one can assume that the return stroke current and current derivative do not change significantly with height at least over the first few hundred meters. Then, according to (1), one can assume that the corona current also behaves in this manner. With this assumption, the first term of (2) reduces to

$$
\begin{aligned}
\frac{d E_{z}(t, D)}{d t} \approx & \frac{1}{2 \pi \varepsilon_{o}} I_{c}(0, t-R / c) \int_{o}^{H} \frac{\sin \theta}{R^{2}} d z \\
& +\frac{1}{2 \pi \varepsilon_{o}} \frac{d I(0, t-R / c)}{d t} \\
& \times \int_{o}^{H} \frac{\left(1-\sin \theta-2 \sin ^{2} \theta\right)}{c R^{2}} d z \quad t>t_{o}
\end{aligned}
$$

where $I_{c}(0, t)$ is the corona current (i.e., the time derivative of the positive charge deposited on the channel) per unit length at the ground end of the channel. We have neglected the radiation field [the last term of (2)] because we are interested in the electric field close to the channel and the radiation field does not make a significant contribution at late times. Before proceeding further, let us place limits on time $t_{o}$. Since we are interested in the electric field in the vicinity of the channel, the length $H$ of the return stroke channel that contributes to the electric field is not more than a few hundred meters. Let us denote the time taken by the return stroke front to traverse this channel section by $t_{p}$. Since the return stroke speed is typically about $1.5 \times 10^{8} \mathrm{~m} / \mathrm{s}$, the value of $t_{p}$ is about a few microseconds. In order to replace (2) by (5), it is necessary to satisfy the following two conditions: 1) $t_{\mathrm{o}}>t_{p}$ and 2) the value of $t_{o}$ is such that, at times longer than $t_{o}$, the return stroke current and the current derivative do not vary significantly over a time interval of $t_{p}$. Since the rapidly varying portion of the current and the current derivative occur within a few microseconds from the beginning of the return stroke, both these conditions can be satisfied by selecting $t_{\mathrm{o}} \approx 5 \mu \mathrm{s}$. Actually, in the case of subsequent return strokes, this time can be reduced further.

Now let us go back to (5). If the close electric field flattens within $15 \mu$ s or so, then the time derivative of the electric field at these times should be close to zero. Thus, for $t>t_{o}$ (for brevity, we will drop the term $R / c$ inside the bracket)

$$
I_{c}(0, t)=-\frac{1}{c} \frac{d I(0, t)}{d t} \frac{\int_{o}^{H} \frac{\left(1-\sin \theta-2 \sin ^{2} \theta\right)}{R^{2}} d z}{\int_{o}^{H} \frac{\sin \theta}{R^{2}} d z} .
$$

For distances less than $100 \mathrm{~m}$ or so, numerical evaluation shows that the ratio of the two integrals in the aforesaid equation is approximately equal to -1 . Thus, one can write

$$
I_{c}(0, t) \approx \frac{1}{c} \frac{d I(0, t)}{d t} \quad t>t_{\mathrm{o}}
$$

This shows that the flattening of the close electric field requires that the temporal variation of the tail of the equivalent corona current at channel sections close to ground is similar to the derivative of the longitudinal return stroke current. 
Let us now consider implications of (7). The corona current represents the rate of change of the positive charge deposited in the corona sheath per unit length of a lightning return stroke channel at a given time. Since the return stroke neutralizes the negative charge in the leader corona sheath, a net positive charge should flow into the corona sheath during the return stroke phase. Thus, the value of the integral from $t=0$ to $t=\infty$ of the corona current has to be positive. However, since the return stroke current derivative is negative after the current peak (also for times $t>t_{\mathrm{o}}$ ), (7) indicates that the corona current also has a negative component. Since the total integral of the corona current is positive, we have to conclude that the initial part of the corona current is positive. This leads to the conclusion that the corona current is bipolar. This is in contrast to the current generation type models available today, all of which assume that the corona current is unipolar [11]. The equivalent corona currents of the current propagation models, however, are predicted to be bipolar [3]. Thus, (7), which, in conjunction with the fact that the integral of the corona current is positive (i.e., positive charge deposition), predicts a bipolar corona current, is consistent with the prediction for the current propagation models, but inconsistent with the assumptions made in the current generation models available in the literature.

\section{SignificANCE OF (7) IN MOdIFIED TRANSMISSION LINE MODELS (MTLM)}

In the transmission line model, the return stroke current is represented by a current pulse propagating without attenuation and distortion along the leader channel with constant speed [4]. Since this model does not take into account the neutralization of the leader charge, several authors have modified this model by introducing a current attenuation factor [5], [6]. These models are known as MTLMs. In one model, the current is assumed to decrease exponentially with height [5], [7], and in the other model, it is assumed to decrease linearly with height [6], [20]. The former is known as the MTLE model and the latter the MTLL model. In the MTLE model, the current at a given point along the return stroke channel can be expressed as

$$
I(z, t)=I(0, t-z / v) e^{-z / \lambda_{e}} .
$$

In the MTLL model

$$
I(z, t)=I(0, t-z / v)\left(1-z / \lambda_{l}\right) .
$$

In these equations, $\lambda_{e}$ and $\lambda_{l}$ define how the return stroke current decreases with height (note that $\lambda_{l}$ was assumed to be equal to the channel length in the original MTLL model), $z$ is the coordinate directed along the vertical, $v$ is the return stroke front speed, and $I(0, t)$ is the current at the base of the channel. Current at the base of the channel of subsequent return strokes is often represented by the following equation [12]:

$I(t)=\frac{I_{1}}{\eta}\left(\frac{t}{\tau_{1}}\right)^{2} \frac{e^{-t / \tau_{2}}}{1+\left(\frac{t}{\tau_{1}}\right)^{2}}+I_{2}\left\{\exp \left(-t / \tau_{3}\right)-\exp \left(-t / \tau_{4}\right)\right\}$.

Since the values of time constants, $\tau_{1}, \tau_{2}$, and $\tau_{4}$ that represent typical current waveforms lie in the range of a few microseconds or less, for late times, the current and the current derivative will vary as $I_{2} e^{-t / \tau_{3}}$ and $-\frac{I_{2}}{\tau_{3}} e^{-t / \tau_{3}}$ respectively. Let us now investigate the consequences of the criterion derived earlier for the MTLMs. The equivalent corona current per unit length corresponding to the MTLE model is given by [3]

$$
\begin{array}{r}
I_{c, \operatorname{MtLE}}(z, t)=\left(\frac{1}{v}+\frac{1}{c}\right) \frac{\partial I(0, t-z / v)}{\partial t} \exp \left(-\frac{z}{\lambda_{e}}\right) \\
+\frac{I(0, t-z / v)}{\lambda_{e}} \exp \left(-\frac{z}{\lambda_{e}}\right) .
\end{array}
$$

For times longer than a few microseconds, we can replace $I(t)$ and $d I(t) / d t$ by corresponding expressions valid for late times. Substituting these in (10) and equating the results obtained for $z \rightarrow 0$ to the expression on the right-hand side of (7), one obtains

$$
\lambda_{e}=v \tau_{3} .
$$

In the case of the MTLL model, the equivalent corona current per unit length is given by [3]

$$
\begin{aligned}
I_{c, \operatorname{MTLL}}(z, t)=\left(\frac{1}{v}+\frac{1}{c}\right) & \frac{\partial I(0, t-z / v)}{\partial t} \\
& \times\left(1-\frac{z}{\lambda_{l}}\right)+\frac{I(0, t-z / v)}{\lambda_{l}} .
\end{aligned}
$$

An analysis similar to that performed earlier leads to the result

$$
\lambda_{l}=v \tau_{3} .
$$

These results show that for the flattening of close electric fields, the decay height constants of the MTL models should vary with the return stroke velocity and the decay rate of the channel base current. Note that the close electric field flattening is also predicted by the MTLL model having a typical channel base current waveform, typical return stroke speed, and a constant value of $\lambda_{l}$ equal to the channel height.

In the MTLE model, the originally suggested value of the decay height constant $\lambda_{e}$ is $2000 \mathrm{~m}$. We have used this model to calculate the electric fields at different distances for four current decay time constants $\tau_{3}$ of $30,50,70$, and $100 \mu \mathrm{s}$. These current waveforms are shown in Fig. 2 together with several examples of the channel base current measured in triggered lightning strokes. In the calculations, the speed of the return stroke was kept constant at $1.5 \times 10^{8} \mathrm{~m} / \mathrm{s}$. Fig. 3(i) shows the electric field at $50 \mathrm{~m}$ predicted by this model. The predicted electric field does not exhibit the flattening observed in experiments. Fig. 3(ii) shows the electric fields calculated at the same distance but by using the decay height constant given by (11). Note the clear flattening of the close electric fields for all values of $\tau_{3}$. However, there is a problem with the use of decay height constants given by (11); they result in a rather large zero crossing time in the distant radiation field. This is illustrated in Fig. 3(iii), where the radiation field at $200 \mathrm{~km}$ as predicted by the MTLE model is depicted.

In order to reduce the distant zero crossing time to acceptable values, one can assume that the decay height constant is heightdependent. Our analysis shows that a suitable decay height constant can be expressed as

$$
\lambda_{e}=\left(v \tau_{3}\right) e^{-z / \lambda_{e m}}
$$




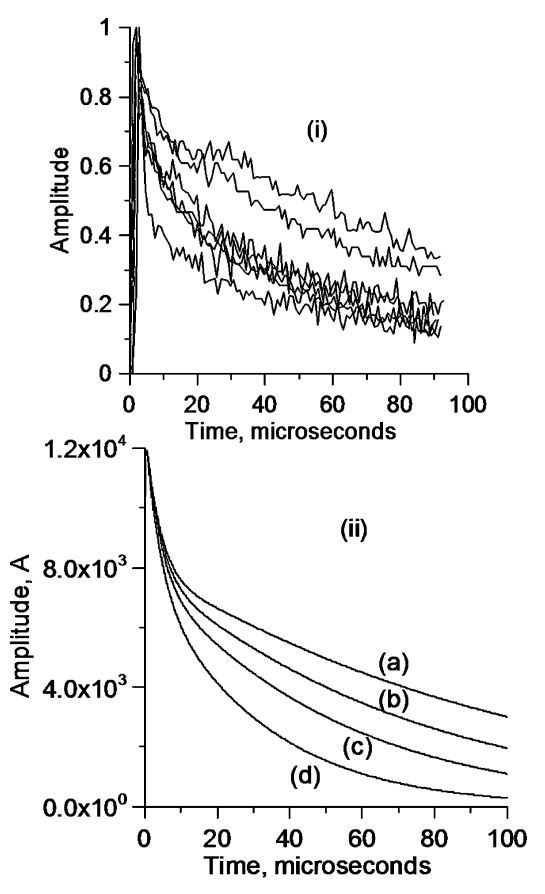

Fig. 2. (i) Several examples of channel base currents measured in triggered lightning [13], [14]. For ease of comparison, the peaks of the waveforms are normalized to unity. (ii) Current waveforms utilized in the calculations presented here. (a) $100 \mu \mathrm{s}$, (b) $70 \mu \mathrm{s}$, (c) $50 \mu \mathrm{s}$, (d) $30 \mu \mathrm{s}$.

with $\lambda_{e m}=4000 \mathrm{~m}$. With this modification, the effective decay height constant at channel sections close to ground is equal to $v \tau_{3}$, in agreement with (11), and for larger heights, it decreases forcing a reduction in the zero crossing time. Fig. 3(iv) and (v) shows the electric field at $50 \mathrm{~m}$ and $200 \mathrm{~km}$, respectively, with this modification. Note that the zero crossing time of the distant (radiation) field is now consistent with measurements. It is important to point out that while modifying the model we did not increase the number of model parameters. In the original MTLE model, the model parameters are the channel base current, return stroke speed, and the decay height constant $\lambda_{e}$. Similarly, in the modified model, the model parameters are the channel base current (which also defines $\tau_{3}$ ), return stroke velocity, and $\lambda_{e m}$.

Now, let us consider the MTLL model. In the MTLL model, the typical value of $\lambda_{l}$ is equal to the total length of the channel, usually, $7000 \mathrm{~m}$. Fig. 4(i) shows the electric field at $50 \mathrm{~m}$, as predicted by this model for four different current decay time constants $\left(\tau_{3}\right)$ of $30,50,70$, and $100 \mu$ s. Fig. 4(ii) shows the electric fields at the same distance for $\lambda_{l}=v \tau_{3}$.

Observe that, in Fig. 4(ii), the close electric field flattens regardless of $\tau_{3}$. However, as in the MTLE model, the zero crossing time of distant (radiation) field becomes unreasonably [at least in case (a)] large with this choice of $\lambda_{l}$. Fig. 4(iii), in which the radiation field at $200 \mathrm{~km}$ is depicted, illustrates this point. In order to reduce the distant field zero crossing time to typically observed values, one can assume $\lambda_{e}$ that varies along the channel. Our analysis shows that a suitable decay height constant can be expressed as

$$
\lambda_{l}=\frac{\left(v \tau_{3}\right) \lambda_{l m}-z\left[\left(v \tau_{3}\right)-\lambda_{l m}\right]}{\lambda_{l m}}
$$
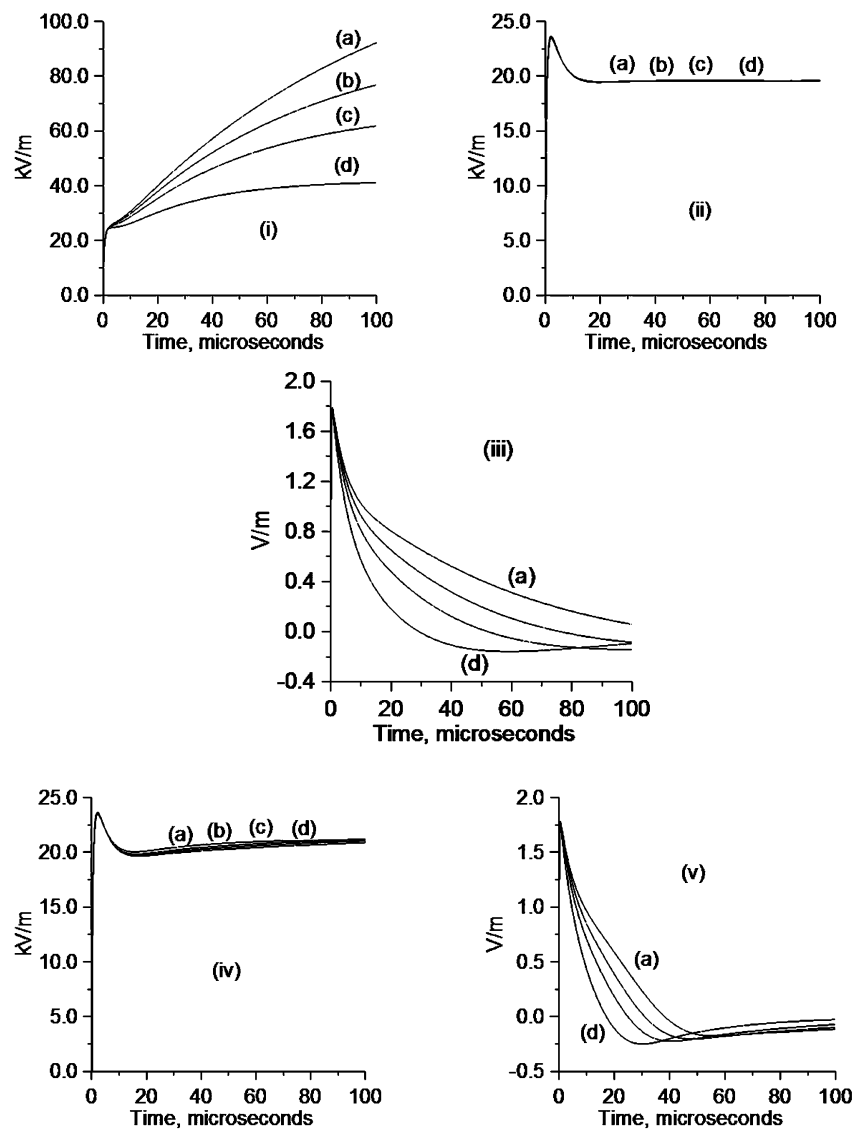

Fig. 3. Electric fields calculated using the MTLE model with four different decay time constants $\tau_{3}$ [(a) $30 \mu \mathrm{s}$, (b) $50 \mu \mathrm{s}$, (c) $70 \mu \mathrm{s}$, (d) $\left.100 \mu \mathrm{s}\right]$ for the channel base current. (i) Electric field at $50 \mathrm{~m}$ with $\lambda_{e}=2000 \mathrm{~m}$. (ii) Electric field at $50 \mathrm{~m}$ with $\lambda_{e}=v \tau_{3}$. (iii) Electric field at $200 \mathrm{~km}$ with $\lambda_{e}=v \tau_{3}$ (labels $\mathrm{b}$ and $\mathrm{c}$ not shown). (iv) Electric field at $50 \mathrm{~m}$ with $\lambda_{e}$ given by (14). (v) Electric field at $200 \mathrm{~km}$ (labels b and c are not shown) with $\lambda_{e}$ given by (14). In the calculations, the speed of the return stroke was kept constant at $1.5 \times 10^{8} \mathrm{~m} / \mathrm{s}$.

with $\lambda_{l m}=7000 \mathrm{~m}$. Fig. 4(iv) shows the electric field at $50 \mathrm{~m}$ and Fig. 4(v) depicts the radiation field at $200 \mathrm{~km}$ with this modification. Again, in the calculations, the speed of the return stroke was kept constant at $1.5 \times 10^{8} \mathrm{~m} / \mathrm{s}$. Note that the zero crossing time of distant field is now more consistent with measurements. As in the original model, the number of model parameters is equal to three. They are the channel base current (which also defines $\tau_{3}$ ), return stroke velocity, and $\lambda_{l m}$. As noted earlier, for typical $v$ and current waveform, the MTLL model is capable of reproducing the characteristic close electric field flattening with a constant value of $\lambda_{l}$ equal to the channel height.

In the aforesaid analysis, we have decreased the zero crossing time by modifying the model parameters. Actually, the zero crossing time of distant radiation field depends also on the channel geometry. Indeed, one can obtain a typical zero crossing time without changing the model parameters by adopting a (physically reasonable) channel geometry that gradually turns from vertical to horizontal as the channel approaches the charge center in the cloud. For example, Fig. 5(a) shows such a geometry. This channel geometry is similar to the channel geometries observed using interferometry [15] and electric field measurements [21], [22]. Fig. 5(b) shows the radiation field at $200 \mathrm{~km}$ 

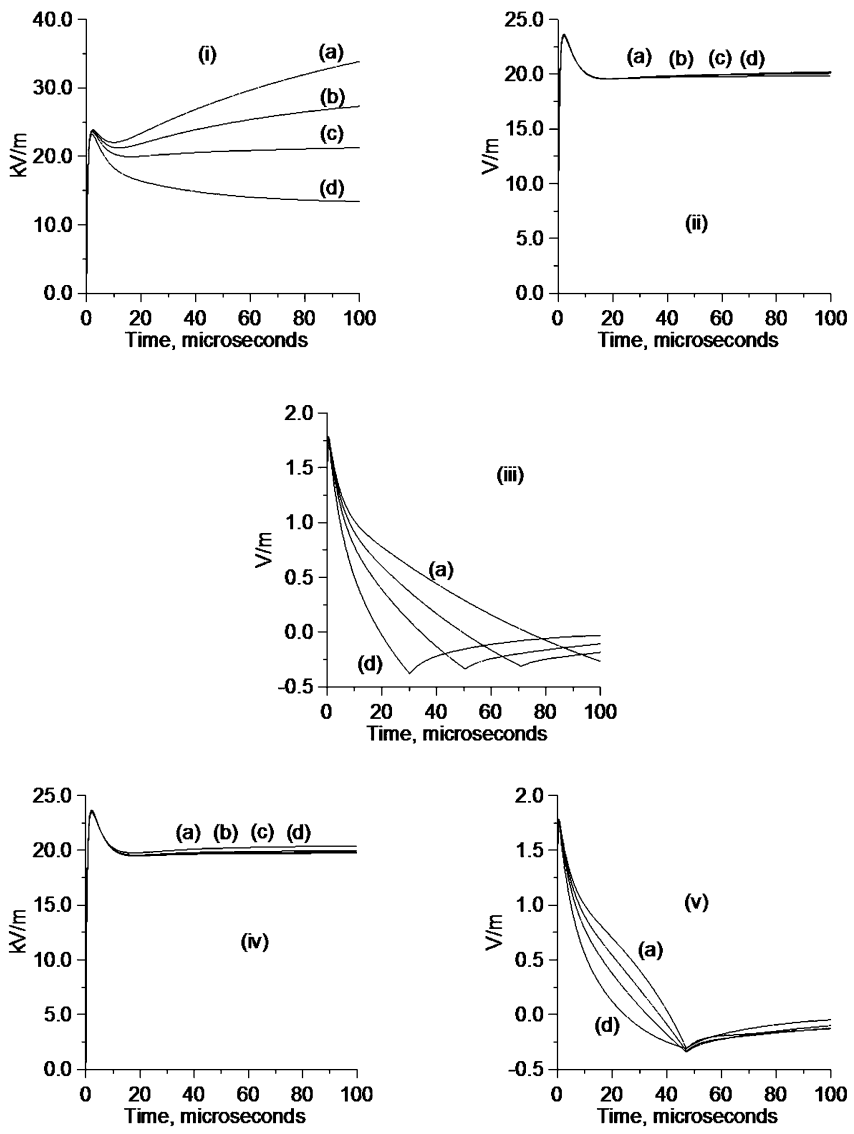

Fig. 4. Electric fields calculated using the MTLL model with four different decay time constants $\tau_{3}$ [(a) $30 \mu \mathrm{s}$, (b) $50 \mu \mathrm{s}$, (c) $70 \mu \mathrm{s}$, (d) $100 \mu \mathrm{s}$ ] for the channel base current. (i) Electric field at $50 \mathrm{~m}$ with $\lambda_{l}=7000 \mathrm{~m}$. (ii) Electric field at $50 \mathrm{~m}$ with $\lambda_{l}=v \tau_{3}$. (iii) Electric field at $200 \mathrm{~km}$ with $\lambda_{l}=v \tau_{3}$ (labels (b) and (c) are not shown). (iv) Electric field at $50 \mathrm{~m}$ with $\lambda_{l}$ given by (15). (v) Electric field at $200 \mathrm{~km}$ (labels (b) and (c) are not shown) with $\lambda_{l}$ given by $(15)$. In the calculations, the speed of the return stroke was kept constant at $1.5 \times 10^{8} \mathrm{~m} / \mathrm{s}$.
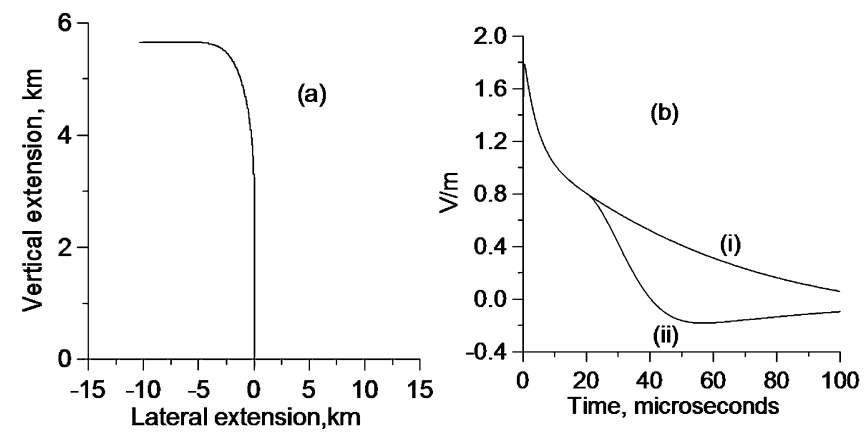

Fig. 5. (a) Channel geometry with a horizontal section in the cloud for calculating the radiation field using the MTLE model. (b) The radiation field at 200 $\mathrm{km}$ as predicted by the MTLE model. (i) Vertical channel. (ii) Channel shown in (a). It was assumed that $\lambda_{e}=v \tau_{3}$ with $\tau_{3}=100 \mu \mathrm{s}$.

predicted by the MTLE model with $\lambda_{e}=v \tau_{3}\left(\tau_{3}=100 \mu \mathrm{s}\right.$ in the example shown) when this channel geometry is used. For comparison purposes, the radiation field obtained with a straight and vertical channel is also shown in the figure. We do not expect the close electric field to be significantly affected by this change in channel geometry because the turning point of the channel is located at $5 \mathrm{~km}$ above the ground, and at $50 \mathrm{~m}$, the electric field is dominated by the charge on the channel sections close to ground.

Even though we have considered examples using MTLE and MTLL models (both are current propagation models), (7) is valid for both current generation and current propagation models. In the case of current generation models, the corona current per unit length at a given height along the return stroke channel can be expressed as [11]

$$
I_{c}(z, t)=I_{\mathrm{co}}(z) e^{-(t-z / v) / \tau(z)}
$$

where $I_{c}(z, t)$ is the corona current per unit length and $\tau(z)$ is the height-dependent discharge time constant. In some models, the discharge time constant is assumed not to vary with height, and in others, it is a function of height. As one can observe from (16), the corona current is unipolar. Since the discharge time constant in almost all the current generation models is not more than a few microseconds, the corona current given earlier can be modified rather easily so that it agrees with (7), for example, by assuming

$$
I_{c}(z, t)=I_{\mathrm{cm}}(z) e^{-(t-z / v) / \tau(z)}+\frac{1}{c} \frac{d I(0, t)}{d t} .
$$

Once the channel base current and the return stroke speed are specified, the same techniques that are applied to obtain $I_{c o}(z)$ can be utilized to obtain $I_{c m}(z)$ in the modified corona current [16], [17]. Observe that, since the duration of the first term in (17) is a few microseconds, the second term, which is negative, will take over at late times making the corona current bipolar. The relationship between the corona current and the close fields as predicted by current generation models will be a subject of future study.

\section{CONCLUSION}

The analysis based on reasonable assumptions concerning the return stroke current shows that, in order for the return stroke models to predict close fields that flatten in $15 \mu$ s or so, the equivalent corona current per unit length should be bipolar and the time signature of the tail of the corona current should be identical to the derivative of the longitudinal return stroke current. This feature is illustrated for the MTLE and MTLL models. We also show that either a height-dependent decay height constant or a lightning channel with an upper horizontal section could be responsible for the typically-observed zero crossing of a distant electromagnetic field.

\section{REFERENCES}

[1] V. Rakov, "Lightning discharges triggered using rocket-and-wire techniques," Recent Res. Dev. Geophys., vol. 2, pp. 141-171, 1999.

[2] M. Rubinstein, F. Rachidi, M. A. Uman, R. Thottappillil, V. A. Rakov, and C. A. Nucci, "Characterization of vertical electric fields $500 \mathrm{~m}$ and $30 \mathrm{~m}$ from triggered lightning," J. Geophys. Res., vol. 100, no. D5, pp. 8863 8872 , May 1995.

[3] V. Cooray, "On the concepts used in return stroke models applied in engineering practice," IEEE Trans. Electromagn. Compat., vol. 45, no. 1, pp. 101-108, Feb. 2003.

[4] M. A. Uman and D. K. McLain, "Magnetic field of lightning return stroke,' J. Geophys. Res., vol. 74, pp. 6899-6910, 1969.

[5] C. A. Nucci, C. Mazzetti, F. Rachidi, and M. Ianoz, "On lightning return stroke models for LEMP calculations," paper presented at the 19th Int Conf. Lightning Prot., Graz, Austria, 1988. 
[6] V. A. Rakov and A. A. Dulzon, "A modified transmission line model for lightning return stroke field calculation," in Proc. 9th Int. Symp. Electromagn. Compat., Zurich, Switzerland, 1991, paper 44H1, pp. 229-235.

[7] F. Rachidi and C. A. Nucci, "On the Master, Lin, Uman, Standler and the modified transmission line lightning return stroke current models," $J$. Geophys. Res., vol. 95, pp. 20 389-20 394, Nov. 1990.

[8] R. Thottappillil, "Computation of electromagnetic fields from lightning discharges," in The Lightning Flash, V. Cooray, Ed. London, U.K.: Inst. Elect. Eng., 2003.

[9] C. Gomes and V. Cooray, "Correlation between the optical signatures and current wave forms of long sparks: Applications in lightning research," $J$. Electrostatics, vol. 43, pp. 267-274, 1998.

[10] D. M. Jordan and M. A. Uman, "Variation in light intensity with height and time from subsequent lightning return strokes," J. Geophys. Res., vol. 88, pp. 6555-6562, 1983.

[11] V. Cooray, "Mathematical modelling of return strokes," in The Lightning Flash, V. Cooray, Ed. London, U.K.: Inst. Elect. Eng., 2003.

[12] C. A. Nucci, G. Diendorfer, M. A. Uman, F. Rachidi, M. Ianoz, and C. Mazzetti, "Lightning return stroke current models with specified channel base current: A review and comparison," J. Geophys. Res., vol. 95, pp. 20395-20 408, 1990.

[13] J. F. Fisher and G. H. Schnetzer, "1993 Triggered lightning test program," Sandia Nat. Labs., Albuquerque, NM, Rep. SAND94-0311.UC 706, 1994

[14] G. H. Schnetzer, J. Chael, R. Davis, R. J. Fisher, and P. J. Magnotti, "1994 triggered lightning test program," Sandia Nat. Lab. Albuquerque, NM, SAND95-1551/2.UC 706, 1995.

[15] X. M. Shao, "The development and structure of lightning discharges observed by VHF radio interferometer," Ph.D. thesis, New Mexico Inst. Mining and Technol., Socorro, NM, 1993.

[16] R. Thottappillil and M. A. Uman, "Lightning return stroke model with height-variable discharge time constant," J. Geophys. Res., vol. 99, pp. 22 773-22 780, 1994.

[17] V. Cooray, "Predicting the spatial and temporal variation of the current, the speed and electromagnetic fields of subsequent return strokes," IEEE Trans. Electromagn. Compat., vol. 40, no. 4, pp. 427-435, Nov. 1998.

[18] D. Wang, N. Takagi, T. Watanabe, V. A. Rakov, M. A. Uman, K. J. Rambo, and M. V. Stapleton, "A comparison of channel base currents and optical signals for the rocket triggered lightning strokes," J. Atmos. Res., vol. 76, no. 1-4, pp. 412-422, 2005.

[19] D. M. Jordan, V. Rakov, W. H. Beasley, and M. A. Uman, "Luminosity characteristics of dart leaders and return stroke in natural lightning," $J$. Geophys. Res., vol. 102, pp. 22.025-22.032, 1997.

[20] V. A. Rakov and A. A. Dulzon, "Calculated electromagnetic fields of lightning return stroke,” Tekh. Elektrodinan., vol. 1, pp. 87-89, 1987.

[21] P. Krehbiel, M. Brook, and R. A. McCrory, "An analysis of the charge structure of the lightning discharges to the ground," J. Geophys. Res., vol. 84, pp. 2432-2456, 1979.

[22] V. A. Rakov, M. A. Uman, D. M. Jordan, and C. A. Priore, "Ratio of leader to return stroke field change for first and subsequent lightning strokes," $J$. Geophys. Res., vol. 95, pp. 16579-16587, 1990.

[23] G. Maslowski and V. A. Rakov, "Equivalency of lightning return stroke models employing lumped and distributed current sources," IEEE Trans. Electromagn. Compat., vol. 49, no. 1, pp. 123-132, Feb. 2007.

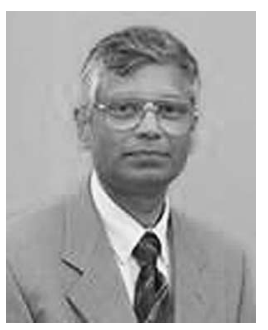

Vernon Cooray received the B.Sc. degree (with first-class honors) in physics from the University of Colombo, Sri Lanka, in 1975, and the Ph.D. degree in electricity with specialization in transients and electrical discharges from Uppsala University, Uppsala, Sweden, in 1982

In the year 2000, he became a Full Professor in electricity with specialization in transients and electrical discharges at the Division for Electricity and Lightning Research, Ångström Laboratory, Uppsala University. He is the author or coauthor of more than 200 scientific papers in physics of lightning and electrical discharges, lightning interaction, and electromagnetic compatibility. He has edited The Lightning Flash (Inst. Elect. Eng., 1981).

Prof. Cooray is the Co-Chair of the International Council on Large Electric Systems (CIGRE) Task Force 33.01.03 on Lightning Interception. He is the Vice President of the Scientific Committee of the International Conference on Lightning Protection and a Member of the Scientific Committee of the International Symposium on Lightning Protection (SIPDA). He is an Editor of the Journal of Lightning Research.

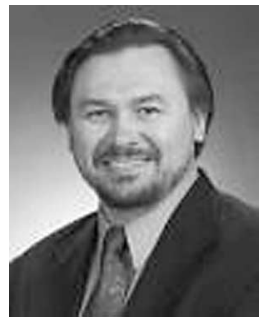

Vladimir A. Rakov (SM'96-F'03) received the M.S and $\mathrm{Ph} . \mathrm{D}$. degrees in electrical engineering from the Tomsk Polytechnic University (Tomsk Polytechnic), Tomsk, Russia, in 1977 and 1983, respectively.

From 1977 to 1979, he was an Assistant Professor of electrical engineering at Tomsk Polytechnic. In 1978, he became involved in lightning research at the High Voltage Research Institute (a division of Tomsk Polytechnic), where from 1984 to 1994 , he held the position of the Director of the Lightning Research Laboratory. He is currently a Professor at the Department of Electrical and Computer Engineering, University of Florida, Gainesville, and Co-Director of the International Center for Lightning Research and Testing. He is the author or coauthor of one book, and more than 400 papers and technical reports on various aspects of lightning, with over 150 papers being published in reviewed journals. He is the holder of more than 30 patents.

Dr. Rakov is a Fellow of the American Mathematical Society as well as the Institution of Engineering and Technology. He is a member of the American Geophysical Union (AGU), the Society of Automotive Engineers, and the American Society for Engineering Education. He is the Chairman of the Technical Committee on Lightning of the Biennial International Zurich Symposium on Electromagnetic Compatibility and former Chairman of the AGU Committee on Atmospheric and Space Electricity.

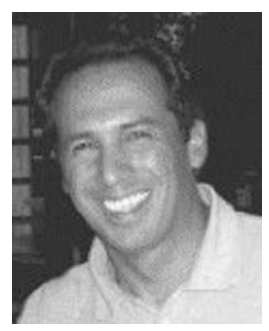

Farhad Rachidi (M'93-SM'02) was born in Geneva, Switzerland, in 1962. He received the M.S. degree in electrical engineering and the Ph.D. degree from the Swiss Federal Institute of Technology, Lausanne, Switzerland, in 1986 and 1991 respectively, where he was with the Power Systems Laboratory until 1996.

In 1997, he joined the Lightning Research Laboratory, University of Toronto, Toronto, ON, Canada, and from April 1998 until September 1999, he was with Montena EMC in Switzerland. He is currently a Professor and Head of the EMC Group, Swiss Federal Institute of Technology. He is the author or coauthor of more than 200 scientific papers published in reviewed journals and presented at international conferences. His current research interests include electromagnetic compatibility, lightning electromagnetics, and electromagnetic field interactions with transmission lines.

Prof. Rachidi is the convener of the joint International Council on Large Electric Systems (CIGRE)-International Conference on Electricity Distribution (CIRED) Working Group on "Protection of MV and LV networks against Lightning," Vice Chair of the European COST Action P18 on "The Physics of Lightning Flash and its Effects," and Chairman of the Subcommittee on "Lightning" of the Technical Committee TC5 of the IEEE Electromagnetic Compatibility Society. He is an Associate Editor of the IEEE TRANSACTIONS ON ELECTROMAGNETIC COMPATIBILITY and the Journal of Lightning Research, and is a member of the scientific committees of various international symposia in the field of electromagnetic compatibilty and lightning protection. He was the recipient of the 2005 IEEE Electromagnetic Compatibility Society Technical Achievement Award and of the 2005 CIGRE Technical Committee Award. In 2006, he received the Blondel Medal from the French Association of Electrical Engineering, Electronics, Information Technology, and Communication (SEE).

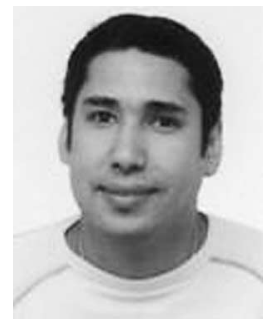

Raul Montaño (S'02-M'06) was born in Venezuela in 1971. He received the B.Sc. degree in electrical power engineering from Simón Bolívar University, Caracas, Venezuela, in 1996, the M.Sc. degree in electrical power engineering from the Royal Institute of Technology, Stockholm, Sweden, in 2000, and the Ph.D. degree from the Division for Electricity and Lightning Research, Uppsala University, Uppsala, Sweden, in 2006.

From August 2002 to March 2006, he was in charge of the High Voltage Laboratory at Uppsala University. In April 2006, he became a Project Leader at the upcoming collaborative research milieu named High Voltage Valley, Ludvika, Sweden. He is the author or coauthor of more than 30 scientific papers presented at international conferences or published in reviewed journals. His current research interests include modeling and experimental investigation of lightning-induced phenomena/effects, behavior of low-voltage surge protection devices, lightning protection, high-voltage engineering, electromagnetic compatibility, electrical power system transients, and electromagnetic transient programs (EMTP-ATP) related issues. 


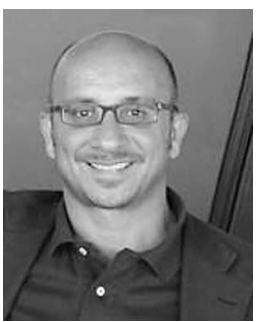

Carlo Alberto Nucci (M'91-SM'02-F'07) was born in Bologna, Italy, in 1956. He received the Graduate degree (with honors) in electrical engineering from the University of Bologna, Bologna, in 1982.

In 1983, he was a Researcher in the Power Electrical Engineering Institute, University of Bologna, where, in 1992, he became an Associate Professor, and in 2000, became a Full Professor and Chair of Power Systems. He is the author or coauthor of more than 200 scientific papers published in reviewed journals or presented at international conferences.

Prof. Nucci is a Fellow of the Institution of Engineering and Technology. He is a member of the IEEE Working Group on "Lightning performance of Distribution lines"; in the International Council on Large Electric Systems (CIGRE), he serves as the Chairman of the Study Committee C4 on "System Technical performance" and is a member of the CIGRE Working group C.401 on "Lightning," of which he is also the Convener. His current research interests include power system transients and dynamics, with particular reference to lightning impact on power lines, system restoration after blackout, and distributed generation. 